\title{
STRATEGI PENGEMBANGAN KAPASITAS KEPEMIMPINAN DALAM MEWUJUDKAN PENINGKATAN KINERJA PENGELOLAH JABATAN PADA BADAN KEPEGAWAIAN DAERAH PROVINSI SULAWESI TENGGARA
}

Oleh:

\author{
La Selo', La Ode Muhammad Elwan', Abdul Rizal ${ }^{3}$ \\ 'Dosen Sekolah Tinggi Ilmu Pertanian Kendari \\ ${ }^{2}$ Dosen Fakultas Ilmu Sosial dan Ilmu Politik Universitas Halu Oleo \\ ${ }^{3}$ Dosen Fakultas Peternakan Universitas Halu Oleo \\ laselostiper77@gmail.com, muh.elwan@uho.ac.id, 89abdulrizal@gmail.com,
}

\begin{abstract}
This study aims to explore the development of leadership capacity and empowerment of staff and to know the factors of leverage in the management of position mutations. This research was conducted in 2014. Analysis of the data used in this study was comparative analysis and SWOT analysis. The results of the research are (1) providing broad opportunities to participate in both relevant and accredited education to support the management of position mutations (2) Encouraging employees to take part in Leadership Training especially for structural office holders (3) Encouraging Civil Servants to participate in tiered Functional Training for functional office holders, (4) Encouraging Civil Servants to participate in Technical Training for staff and office holders in order to strengthen the implementation of tasks, (5) Encouraging Civil Servants to attend short courses, (6) developing inhouse training in the context of mastering assignments for staff. The policy strategy that can be carried out is to improve the quality of the apparatus resources through formal education of SI, S2, S3 and leadership training and tennis training, improve solid policy matching in the field of apparatus development and improve the facilities and infrastructure of personnel management information systems.
\end{abstract}

Keywords : Development, Capacity, Leadership, Performance 


\section{PENDAHULUAN}

Sebagai prasyarat dalam mewujudkan pemerintahan yang efektif diperlukan pembaharuan organisasi dan aparatur pemerintah. Dengan demikian, nilai-nilai setiap aktor penyelenggara pemerintahan dan pembangunan harus benar-benar mampu memainkan perannya dibidang pemerintahan umum, pembangunan dan pelayanan kepada masyarakat (Achmad S. Ruky, 2001).

Tanggungjawab pendayaagunaan dan pembinaan aparatur bersifat lintas internasional dan sektoral, baik ditingkat pusat maupun daerah (William N. Dunn, 2003). Undang-undang Nomor 43 tahun 1999 tentang Perubahan Undang-undang Nomor 8 tahun 1974 tentang pokok-pokok kepegawaian mengisyaratkan bahwa Pembina kepegawaian daerah memiliki andil besar terhadap pembinaan pegawai negeri sipil yang bersifat (uni fied) dimana pembina kepegawaian daerah memiliki kewenangan besar namun harus sesuai dengan ketentuan yang berlaku.

Pendayagunaan dan pembinaan Pegawai Negeri Sipil pusat dan daerah mengacu pada kebijakan pemerintah utamanya dalam hal netralitas Pegawai Negeri Sipil, penataan perangkat kelembagaan, birokrat professional, pelayanan publik, akuntabilitas kinerja aparatur dan perubahan mind set aparatur (LAN-RI, 2005).

Perkembangan lingkungan strategis eksternal dan internal dalam rangka membangkitkan dan menumbuhkan peran nilai positif dan kinerja belum seirama dengan pengembangan kapasitas manajemen yang memadai dalam hal konsepsi paradigm, kebijakan publik dan manajemen strategis (Agustinus Sri Wahyudi, 1986).

\section{METODE PENELITIAN}

Jenis penelitian ini adalah jenis deskriptif dengan menggunakan pendekatan kualitatif. Pengumpulan data dilakukan melalui studi kepustakaan dengan cara mempelajari, mengutip dan menelaah literatur-literatur serta bahan-bahan yang mempunyai hubungan dengan permasalahan yang akan dibahas. Selanjutnya data tersebut diolah, diteliti dan dievaluasi, kemudian diklasifikasikan sesuai dengan materi pembahasan masalah. Sumber data yang digunakan oleh penulis yaitu buku teks dan kebijakan-kebijakan seperti undang-undang, peraturan pemerintah, keputusan menteri, peraturan bupati dan sumber-sumber lainnya yang berhubungan dari internet dan koran. Teknik analisis yang digunakan yaitu analisis komparasi dan analisis SWOT.

\section{PEMBAHASAN}

Dalam rangka untuk mewujudkan daya guna dan hasil guna pembinaan aparatur dalam menghadapi perubahan paradigm masa kini dan masa yang akan datang. Dalam penelitian ini memfokuskan pada prinsip- 
Vol.1 No.3. Oktober 2018. pp.33-39. Copyright@2018 PUBLICUHO Faculty of Social and Political Sciences Halu Oleo University, Kendari, Southeast Sulawesi, Indonesia. ISSN: 2460-058X | e-ISSN: 2621-1351. Open Access at: http://ojs.uho.ac.id/index.php/PUBLICUHO

Jounal publiuho is licensed under a Creative Commons Attribution 4.0 International License, which permits unrestricted use, distribution, and reproduction in any medium, provided the original work is properly cited.

prinsip kepemimpinan baru dan dapat diyakini mampu menjadi dasar dalam menunjunag efektivitas pembinaan melalui pengelolaan jabatan.

\section{Pola Perilaku Sistim Dalam Pengelolaan Jabatan}

Menduduki suatu jabatan utamanya jabatan struktural harus memenuhi syarat jabatan yang ditentukan oleh peraturan perundang-undangan yang berlaku. Persyaratan yang ditentukan adalah sebagaimana dalam peraturan Pemerintah Nomor 100 tahun 2000 jo Peraturan Pemerintah Nomor 13 tahun 2002 tentang Pengangkatan Jabatan Pegawai Negeri Sipil dalam jabatan struktural harus memenuhi syarat kepangkatan, pendidikan formal tertentu, Diklat Kepemimpinan, Diklat Teknis, dan Daftar Urut Kepangkatan. Setiap pengangkatan harus diusulkan oleh Kepala SKPD minimal tiga orang calon. Untuk itu, dalam rangka memperlancar pengelolaan jabatan diperlukan pengetahuan dan keterampilan bagi pengelolah mutasi jabatan (Shifting The Burden).

\section{Faktor Pengungkit Sebagai Isu Strategis}

Penyelesaian masalah yang paling mendasar untuk mendapatkan perhatian bagi pemangku jabatan pengelolah kepangkatan pada Badan Kepegawaian Daerah Provinsi Sulawesi Tenggara dan merupakan agenda penting dalam pembinaan aparatur adalah (l) memberikan kesempatan yang luas mengikuti pendidikan baik SI, S2 dan S3 yang relevan di Perguruan Tinggi Negeri maupun Swasta yang terakreditasi untuk mendukung pengelolaan mutasi jabatan (2) Mendorong Pegawai Negeri Sipil untuk mengikuti Diklat Kepemimpinan khususnya bagi pemangku jabatan struktural eselon IV, III, II dan I serta PNS potensial untuk dipromosikan dalam jabatan struktural, (3) Mendorong Pegawai Negeri Sipil untuk mengikuti Diklat Fungsional berjenjang bagi pemangku jabatan fungsional, (4) Mendorong Pegawai Negeri Sipil untuk mengikuti Diklat Teknis bagi staf dan pemangku jabatan dalam rangka memantapkan pelaksanaan tugas, (5) Mendorong Pegawai Negeri Sipil untuk mengikuti kursus singkat, (6) mengembangkan training in house dalam rangka penguasaan tugas bagi staf.

\section{Evaluasi Kebijakan}

Suatu kebijakan menuntut pertimbangan sumber daya sangatlah menentukan dalam suatu implementasi kebijakan. Dalam proses implementasinya tentu dibutuhkan strategis kebijakan publik yang diantaranya adalah sosialisasi dan diseminasi, team kerja dan organisasi, penyusunan kebijakan dan pengembangan aparatur (Siagian, 1998). Dalam rangka peningkatan pengelolaan mutasi jabatan, maka kebijakan pengembangan aparatur cukup signifikan dan diyakini dalam meningkatkan kinerja organisasi. Untuk meningkatkan lembaga 
Badan Kepegawaian Daerah Provinsi Sultra sesuai dengan perannya diperlukan perioritas pelaksanaan program agar sumber daya yang dibutuhkan memiliki nilai tambah (value addid).

Dalam rangka untuk mengoptimalkan capaian program yang telah ditetapkan sebagaimana peran yang harus dilakukan dari seorang pemimpin diperlukan evaluasi atas strategis kebijakan program yang telah ditetapkan seperti input, process, output, outcome, benefit dan impact.

\section{Strategi Pengembangan Kapasitas Kepemimpinan}

Dalam menentukan strategi pengembangan kapasitas dipengaruhi oleg beberapa faktor baik factor internal maupun eksternal. Analisis faktor internal yang berpengaruh adalah yang bersifat kekuatan (Streagth) dan kelemahan (Weaknesess).

Tabel l. Faktor-Faktor Internal

\begin{tabular}{|l|l|}
\hline \multicolumn{1}{|c|}{ Kekuatan (Streagth) } & \multicolumn{1}{|c|}{ Kelemahan (Weaknesess) } \\
\hline 1. Adanya motivasi pegawai yang tinggi & l. Sarana pendukung masih kurang \\
2. Jumlah pegawai yang memadai & 2. Kemampuan dan ketrampilan relative masih \\
3. Adanya uraian tugas dan fungsi yang jelas & 3. Data jabatan aparatur masih terbatas \\
4. UU No 43 tahun 1999 & 4. Dana terbatas \\
\hline
\end{tabular}

Sumber: Hasil analisis, 2018

Tabel 2. Faktor-Faktor Eksternal

\begin{tabular}{|c|c|}
\hline Peluang (Oportunities) & Ancaman (Treats) \\
\hline $\begin{array}{l}\text { 1. Adanya motivasi pegawai yang tinggi } \\
\text { 2. Jumlah pegawai yang memadai } \\
\text { 3. Adanya uraian tugas dan fungsi yang jelas } \\
\text { 4. UU No } 43 \text { tahun } 1999\end{array}$ & $\begin{array}{l}\text { 1. Sarana pendukung masih kurang } \\
\text { 2. Kemampuan dan ketrampilan relative masih } \\
\text { terbatas } \\
\text { 3. Data jabatan aparatur masih terbatas } \\
\text { 4. Dana terbatas }\end{array}$ \\
\hline
\end{tabular}

Sumber: Hasil analisis, 2018

Berbagai informasi tentang masalah dalam lingkungan internal dan eksternal dari pencermatan strategis diproses dengan melakukan pembobotan dan rating untuk menjadi suatu kesimpulan strategis. 
Vol.1 No.3. Oktober 2018. pp.33-39. Copyright@2018 PUBLICUHO Faculty of Social and Political Sciences Halu Oleo University, Kendari, Southeast Sulawesi, Indonesia. ISSN: 2460-058X | e-ISSN: 2621-1351. Open Access at: http://ojs.uho.ac.id/index.php/PUBLICUHO

Jounal publiuho is licensed under a Creative Commons Attribution 4.0 International License, which permits unrestricted use, distribution, and reproduction in any medium, provided the original work is properly cited.

Tabel 3. Perioritas Analisis Faktor Internal

\begin{tabular}{|c|c|c|c|c|}
\hline Faktor Internal & Bobot & Rating & Skor & Skala Perioritas \\
\hline \multicolumn{5}{|l|}{ Kekuatan (S) } \\
\hline Motivasi pegawai & 15 & 4 & 60 & I \\
\hline Jumlah pegawai & 10 & 4 & 40 & II \\
\hline Tugas dan fungsi & 15 & 2 & 30 & III \\
\hline UU No. 43 Tahun 1999 & 10 & 2 & 20 & IV \\
\hline \multicolumn{5}{|l|}{ Kelemahan (W) } \\
\hline Sarana & 15 & 4 & 60 & I \\
\hline Kemampuan dan ketrampilan staf & 10 & 4 & 40 & II \\
\hline Data jabatan & 15 & 2 & 30 & III \\
\hline Dana & 10 & 2 & 20 & IV \\
\hline
\end{tabular}

Sumber: Hasil analisis, 2018

Tabel 4. Perioritas Analisis Faktor Eksternal

\begin{tabular}{|c|c|c|c|c|}
\hline Faktor Eksternal & Bobot & Rating & Skor & Skala Perioritas \\
\hline \multicolumn{5}{|l|}{ Peluang (0) } \\
\hline UU bidang pegawai & 20 & 4 & 80 & I \\
\hline Renstra Sultra & 15 & 4 & 60 & II \\
\hline Desentralisasi & 10 & 4 & 40 & III \\
\hline Dukungan pimpinan & 10 & 2 & 20 & IV \\
\hline \multicolumn{5}{|l|}{ Ancaman (T) } \\
\hline Campr tangan stakeholder & 10 & 2 & 20 & IV \\
\hline Orientasi karir dibandingkan kinerja & 15 & 3 & 45 & I \\
\hline Syarat administrasi & 10 & 4 & 40 & II \\
\hline Koordinasi & 10 & 3 & 30 & III \\
\hline
\end{tabular}

\section{Sumber: Hasil analisis, 2018}

Sebagai upaya untuk mendayagunakan factor-faktor internal dan eksternal diperlukan strategi antar variabel kedalam strategi SO, WO, ST dan WT. Adapun strategi yang dimaksud adalah sebagai berikut:

\section{Starategi SO}

1. Mengoptimalkan motivasi pegawai dalam pelaksanaan diklat aparatur 
2. Mendayagunakan jumlah staf dalam pelaksanaan renstra

3. Memanfaatkan tugas dan fungsi untuk mendukung otoda

4. Memanfaatkan UU No. 43 tahun 1999 dalam member dukungan pimpinan

\section{Strategi WO}

1. Memanfaatkan UU bidang kepegawaian dalam efisiensi sarana

2. Memanfaatkan renstra dalam meningkatkan kemampuan dan keterampilan

3. Memanfaatkan fungsi desentralisasi dalam mengelolah data jabatan

4. Memanfaatkan dukungan pimpinan dalam mengatasi dana.

\section{Strategi ST}

1. Meningkatkan motivasi pegawai untuk menghindari campur tangan stakeholders

2. Memanfaatkan jumlah pegawai untuk menghilangkan orientasi karir dibandingkan kinerja

3. Memanfaatkan pelaksanaan tupoksi untuk menghindari syarat administrasi

4. Menggunakan UU No 43 tahun 1999 untuk menghindari lemahnya koordinasi

\section{Strategi WT}

1. Meningkatkan sarana untuk menghindari campur tangan stakeholders

2. Meningkatkan kompentensi untuk peningkatan kinerja

3. Memantapkan data jabatan dalam administrasi kepegawaian

4. Meningkatkan dana untuk kegiatan padu serasi kebijakan

\section{KESIMPULAN}

Perubahan paradigma lingkungan strategis sistim penyelenggaran pemerintahan dan pembangunan dengan dukungan pegawai negeri professional ternyata tidak mudah untuk merumuskan model yang bersifat universal dan berlaku untuk semua kalangan karena bertitik tolak dengan norma kepegawaian yang mengisyaratkan pembinaan bersifat unified, pemersatu dan perekat NKRI dimana kebijakan dibuat oleh pemerintah pusat dan pelaksanaannya didesentralisasikan ke daerah.

Peranan kepemimpinan cukup signifikan dalam mengaktualisasikan pemenuhan tuntutan model pembinaan pegawai negeri sipil dengan standar, norma, sistim kerja dan tata nilai didunia birokrasi mulai sistim pengadaan PNS, pengelolah mutasi, pembinaan dan sistim penggajian yang dideskripsikan dalam model pembinaan etika.

Pengembangan kapasitas kepemimpinan dibidang kepegawaian ditandai dengan kemampuan memberikan solusi pemecahan masalah pokok pembinaan pegawai negeri sipil secara sistimatik dengan memberikan model 
factor pengungkit (reverage) sehingga sasaran yang dituju dapat diwujudkan secara berdayaguna dan berhasilguna.

Untuk menghindari tragedi bersama dalam pengelolaan mutasi jabatan sebagai peningkatan karier sekaligus membangkitkan dan memperkuat kelembagaan yang terbuka dengan memperhatikan aspek kepentingan otonom, kepentingan stabilitas, keadilan dan keseimbangan etnis dalam jabatan birokrasi yang ada.

Strategi kebijakan yang dapat dilakukan adalah meningkatkan kualitas sumberdaya aparatur melalui pendidikan formal SI, S2, S3 dan diklat kepemimpinan serta diklat tenis, meningkatkan padu serasi kebijakan dibidang pembinaan aparatur dan meningkatkan sarana dan prasaranan sistim informasi manajemen kepegawaian.

\section{DAFTAR PUSTAKA}

Achmad S. Ruky, 2001, Sistim Manajemen Kinerja Performance Management Systim Panduan Praktis Untuk Merancang dan Meraih Kinerja Prima. Penerbit PT Gramedia Pustaka Utama Jakarta.

Agustinus Sri Wahyudi, (1996). Manajemen Strategik. Pengantar Proses Berfikir Strategik. Binarupa Aksara. Jakarta.

LAN-RI, 2005. Buku III Landasan dan Pedoman Pokok Penyelenggaraan dan Pengembangan Sistim Administrasi.

Sondang P. Siagian, 1998. Manajemen Sumber Daya Manusia. Penerbit Bumi Aksara. Jakarta.

William N. Dunn. 2003. Public Policy Analysis an Introduction, Univercity of Pitts Burgh Kanada. 